\title{
Орлова Э.А. \\ Зачем нужна социология культуры
}

Аннотация: Предметом исследования являются факторы, обусловившие становление социологии культуры. Объектом исследования являются концепции (определения) культуры в социологии и культурной антропологии. Автор подробно рассматривает такие аспекты темы, как преодоление существующих дисциплинарных разделений, особое внимание к социокультурной динамике, переход от субъект-объектной трактовки социокультурной реальности к интерсубъективной, отказ от субстанционализма в трактовке общества и культуры. Особое внимание уделяется формированию современной социологии культуры как ответу на смену познавательных парадигм. Анализ содержания концепции (определения) понятия «культура» в социологии и антропологии; динамический анализ изменений предметной области социологии в связи с изменением трактовки понятия «культура». Основным выводом исследования является обоснование необходимости социологии культуры в ее современном варианте. Особым вкладом автора в исследование темы является анализ факторов, обусловивших формирование современной социологии культуры. Новизна исследования заключается в том, что тема рассматривается в контексте смены познавательных парадигм в рамках социологии.

Ключевъе слова: Культура, культурная антропология, марксизм, позитивизм, познавательная парадигма, постмодерн, рационализм, структурализм, структурный функционализм, феноменологическая социология.

Review: The subject of the research is the factors that conditioned the development of the sociology of culture. The object of the research is the concepts and definitions of culture in social studies and cultural anthropology. The author examines such aspects of the topic as overcoming disciplinary differences, special attention to the sociocultural dynamics, transfer from the subject-object interpretation of the sociocultural reality towards intersubjective one and refusal of substantialism in culture and society. Special attention is paid to the development of the contemporary sociology of culture as a response to the cognitive paradigm shift. Analysis of the contents of the concept (definition) of culture in social studies and anthropology and dynamic analysis of the changes of the matter of social studies as a result of changes in the definition of culture are analyzed. The main contribution of the research is the statement of the demand for the modern variant of the sciology of culture. The author's contribution to the topic is the analysis of the factors that determine the development of the contemporary sociology of culture. The novelty of the research is caused by the fact that the author views the topic in terms of the cognitive paradigm shift and as part of social studies.

Keywords: Culture, cultural anthropology, Marxism, positivism, cognitive paradigm, post-modernity, rationalism, structuralism, structural functionalism, phenomenological sociology.

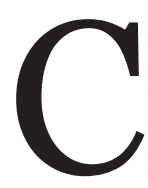
овременные ориентации в области социологии культуры стали проявляться в связи со сменой познавательных парадигм в социальных науках. Американский философ Р. Рорти отмечает, что усилившееся в этот период «...ощущение, что потеряна целостность, имеет своей причиной то обстоятельство, что отказ от традиционной Теологико-метафизической веры в Единство Реальности и Истины (веры в то, что есть Одно Истинное Описание того, Какова Истинная Реальность) совпал с упадком веры в то, что мир непременно станет лучше...» [1].

Такое изменение, согласно Рорти началось с Дж. Милля и У. Джеймса, пытавшихся пре- одолеть метафизическую веру в то, что вселенная и Истина должны находиться в отношениях Единства. Кроме того, Ф. Ницше и У. Джеймс заменили метафизические понятия «Реальность» и «Природа» на концепт окружения. Внешнее воздействие признавалось, но считалось, что люди не обязаны подчиняться ему, как проявлению метафизики Природы или Разума. Задача людей - регулировать его или адаптироваться к нему, а не подчиняться в силу моральных обязательств. «Для Ницше и Джеймса идея о том, что у нас есть моральный долг человека состоит в угождении Богу». Соответственно утвердилось представление, «то существует множество различных, но равноценных вариантов 
человеческой жизни. Принцип подчинения единообразию стал менее принудительным» [1] Итак, если в эпоху модерна в философии и науке предпринимались интеллектуальные попытки сохранить представление о единстве и целостности Мира в условиях совершенно очевидной изменчивости, то с конца 1960-х гг., которые считаются началом постмодерна, ситуация существенным образом начала меняться.

\section{Пересмотр оснований теоретической социологии в условиях смены познавательных парадигм}

В этих обстоятельствах социологи, наиболее чувствительные к переменам, предпринимают попытки пересмотра исходных допущений своей науки и формирования новых фундаментальных оснований. Согласно Н. Луману, это необходимо потому, что к классическому вопросу социологии «Что происходит?» следует добавить еще один: «Что за этим кроется»? Если ответ на первый обеспечивает современная эмпирическая социология мейнстрима, то второй прямо связан с теоретической деятельностью. Речь идет о рефлексии к исходным допущениям, на которых строится сегодня социологическое знание, и построении новых объясняющих моделей.

Значимость такой работы для перехода на новый уровень изучения общества еще в 1970-х гг. продемонстрировали Э. Гоулднер в отношении теории и Р.Фридрихс применительно к методологии. Позже эту необходимость подчеркивал Э.Гидденс: «Концептуальное обновление (вкупе с эмпирическими исследованиями), по крайней мере, столь же важно в социальных науках, как и формулировка новых обобщений. Ибо это обновление может содержать в себе такие «способы видения» социального мира, которые недоступны непрофессионалу. Оно позволяет увидеть скрытые возможности данного набора социальных институтов и обнаружить такие их аспекты, о существования которых никто не подозревал» [2].

Однако, как оказалось, подобные изменения не могут ограничиваться частными поправками к классическому наследию. Социологи вслед за Т. Куном, П. Фейерабендом, М. Фуко и др. заговорили о необходимости смены познавательных парадигм. В то же время, соглашаясь с С. Тулмином, они пола- гали, что это не означает полного отказа от ранее сложившихся теорий. Каждое обновление предполагает соотнесение с ними. В изменившемся познавательном контексте их релевантные компоненты, меняя значение, включаются в более современные разработки, а предшествующие теории утрачивают субстанциональный смысл и приобретают инструментальный статус. Еще одно важное изменение в социологии заключалось в признании погруженности исследователя в собственную культуру и наложения ее стандартов на наблюдения и выводы, относящиеся к изучаемым обществам. Иными словами, представления о них обусловлены не только и не столько внутринаучными факторами.

Таким образом, смена тематики исследований, точки зрения на предметную область изучения («позиции наблюдателя») сопровождается серьезными познавательными проблемами. При таких обстоятельствах нередко теории остаются незавершенными, их эвристический потенциал используется не в полной мере из-за того, что в быстро меняющейся социальной реальности исследователи не столько обращаются к исходным основаниям своей профессиональной деятельности, сколько стремятся осмыслить, «что происходит». Однако обычно для этого имеющегося фундаментального знания оказывается недостаточно. «Условием возможности истины социальной науки является объективация подвижного различия между объективированным и необъективированным. Это различие производит, в свою очередь, различия между транзитивным и нетранзитивным, между действительным и возможным, наглядным и наблюдаемым, между существующим и наблюдаемым и др. Пользуясь ими, мы можем усмотреть, что не только не все наблюдаемое наглядно, но и не все существующее наблюдаемо» [3]. Если этого не признавать, то создаются ad hoc допущения, модели, гипотетические объяснения, которые впоследствии оказываются либо поверхностными, либо частными. И полученное знание становится скорее материалом для дальнейших анализа и обобщения, чем теориями, обеспечивающими систематическое описание объекта изучения, объяснение, диагноз и прогноз его состояний.

Совершенно очевидно, что в условиях смены познавательных парадигм речь идет о необходимости фундаментального обоснования социологического знания. В со- 
временной социологии действительно наступил период серьезного пересмотра теоретических и методологических исходных допущений, который в то же время тесно связан с ключевыми чертами изменяющейся социокультурной реальности.

Можно выделить основные условия для этого, образующие сегодня проблемное поле, в пределах которого следует осуществлять основную поисковую активность.

Междисциплинарность. В настоящее время активно обсуждается вопрос о необходимости междисциплинарного решения каждой конкретной исследовательской проблемы. На методологическом, инструментальном уровне это поможет преодолеть традиционные для социологии дуализмы «структура/действие», «система/конфликт». Соответственно осуществим переход к контекстуальному видению объекта исследования. Однако требуется введение таких теоретически разработанных концептов, как интеракция, интерпретация, социальные практики и т. п. Среди сторонников этой позиции можно назвать П. Бурдье, Э. Гидденса, И. Гофмана, Д. Крейн, Н. Лумана, Ю. Хабермаса.

Преодоление существующих дисциплинарных разделений. Э. Гидденс, например, считает, что в условиях смены познавательных парадигм не следует придерживаться представления о суверенности социологии, которое сложилось еще в конце XIX в. и разделяется представителями мейнстрима в этой науке до сих пор. «Возникает теоретический синтез, который вновь придаст связность социологическим дискуссиям... Мы должны признать, что сохранение в социологии абсолютной четкости ее границ и «неприкосновенности владений» не только невозможно, но и нежелательно...Социология, конечно, обладает некоторым набором понятий и теорий, которые, по всей вероятности, составляют ее исключительную прерогативу, но в методологическом отношении она далеко не так прочно изолирована от остальных социальных и гуманитарных наук, как многие были склонны считать» [4].

Особое внимание к современной социокультурной динамике. Признание сложности и динамичности социокультурной реальности уже обнаружило несостоятельность ее описания и объяснения с помощью только социально-научных теорий, характерных для периода модерна. Сегодня социологам приходится «анализировать социум разной дина- мической сложности, находящийся в разных темпомирах, подверженный парадоксальным разрывам и синтезам, имеющий тенденцию к дисперсии, да еще рефлектировать по поводу самых разных амбивалентностей: глобализации и локализации, инноваций и процессов структурно-функционального «старения» социума, появления десоциализированного социума и новых социальных идентификаций; возникновения новых типов рациональностей и иррациональностей» [5]. В то же время для получения достоверных данных о такого рода феноменах и для их анализа пока не существует установившейся теоретической системы координат, в рамках которой они поддавались бы надежной интерпретации и теоретически приемлемому объяснению.

Переход от субъект-объектной трактовки социокультурной реальности к интерсубъективной. В рамках социологии модерна для объяснения движущих сил общественных процессов широко и нерефлексивно использовалась оппозиция субъекта и объекта. Однако в теоретических построениях Э. Дюркгейма, М. Вебера, а позже Т. Парсонса можно проследить неудовлетворенность такой упрощенной трактовкой социальной реальности. Обращение к понятию ценности стало попыткой привнести в нее измерение, передающее отношение людей и к собственной активности, и к общественным явлениям, которые они сами порождали и с которыми им приходилось иметь дело. В то же время в рамках культурной антропологии давно используются понятия значения и смысла социальных и культурных явлений. По словам Р. Рорти, такая позиция оказалась несводимой ни к субъективности, ни к объективности и, можно прибавить, ни к ценности. Он подчеркивал, что начиная с Ч. Пирса и Дж. Дьюи, эти понятия начали трактоваться как своего рода инструменты для объяснения конституирования социокультурной реальности и совместного существования людей в ее пределах. Таким образом, было положено начало для преодоления метафизического противопоставления субъекта и объекта. Теоретико-методологическую основу изучения культуры в этом направлении составили лингвистическая философия и сопутствующие ей способы социально-научного познания. Социология долгое время находилась за пределами этого интеллектуального течения. В настоящее время некоторые из социологов, пре- 
одолевших инерцию мейнстрима, все большее внимание уделяют изучению значений и смыслов того, что происходит в обществе и культуре, и не углубляются в рассуждения о субъект-объектных отношениях.

Отказ от субстанциализма в трактовке общества. Конструктивистские начала в понимании процессов и результатов научного познания, которые проявились еще в период раннего модерна, в социальных науках второй половины XX в. позволили некоторым из социологов преодолеть привычку реифицировать понятия общества и культуры. Иными словами, отказаться от представления о том, что существует априорная, независимая от людей социокультурная реальность, которую можно познать при помощи врожденной антропологической способности к отражению. Такую позицию Э.Кассирер назвал субстанциалистской.

В настоящее время социальная реальность начинает трактоваться с реляционной точки зрения: предполагается, что рассматривать условия, процессы и результаты совместного существования людей как производные взаимодействий и коммуникаций более продуктивно, чем искать специфичную для них «субстанцию». Это и привело к усилению конструктивистской позиции в изучении общества.

Начиная с работы П. Бергера и Т. Лукмана «Социальное конструирование реальности» [6], предложенное ими использование познавательных принципов феноменологии вошло в состав современного социологического теоретизирования.

Конструирование здесь понимается двояким образом. С одной стороны, авторы как последователи Э.Гуссерля исходят из того, что, познавая окружение и свои отношения с ним, люди сами выстраивают специфичный для них жизненный мир. С другой - исследователь, изучая его, конструирует специальный социологический инструментарий, отвечающий требованиям научности и позволяющий структурировать и изучать предметную область, соответствующую решаемой проблеме. Изменения такого рода привели к теоретическому обоснованию так называемой микросоциологии.

Как известно, в предыдущий период доминировали иные тенденции. В рамках теории структурного функционализма изучались главным образом «крупные формы» социетального уровня (экономические, политиче- ские институты, социальная структура общества, крупномасштабные социальные движения и т. п.). С другой стороны, имели распространение обобщения (без серьезных теоретических обоснований) эмпирических данных, полученных в ходе полевых (теории «среднего уровня», предложенные Р. Мертоном) или лабораторных (теория групповой динамики) исследований. Однако ни те, ни другие не вносили инноваций в исходные допущения теоретические или методологические допущения социологии, т. е. не выходили за пределы общепринятой социально-философской парадигмы модерна.

Более того, между «теоретиками» и «эмпириками» существовало взаимное неприятие. «Те, кто посвятил себя изучению непосредственных контекстов социального взаимодействия, часто скептически воспринимают «реальность» более масштабных типов социальной организации и социальных изменений. Per contra, те, кто имеет дело с более крупными формами институционального порядка, стремятся избежать «микросоциологии» как чего-то крайне тривиального. Феноменология и этнометодология сделали более рельефными недостатки обеих соперничающих позиций. Оказалось, что мелочи жизни вовсе не лишены интереса и не чужды социальных последствий. Многие характерные особенности обыденных социальных действий теснейшим образом связаны с длительными масштабными процессами воспроизводства социальных институтов. В то же время «макроструктурные» свойства социальных систем воплощены в самых случайных и мимолетных локальных интеракциях. Здесь существует немало сложных теоретических и эмпирических проблем, которые ждут своего обсуждения. Но можно с достаточной долей уверенности утверждать, что их решение будет связано с анализом рекурсивной природы социальной жизни»[7].

Это направление теоретизирования значимо, по крайней мере, в двух существенных отношениях. Во-первых, в отличие от структурного функционализма, ориентированного на выявление строения социальной системы, микросоциологическое направление связано с изучением механизмов установления, поддержания и изменения элементов и связей как внутренних, так и внешних для системы. Во-вторых, при изучении «микрофеноменов» предполагается необходимое их соотнесение с социальными образованиями, относящимися к «макроуровню». В этом случае решается 
задача, связанная с преодолением методологической дихотомии «инсайдер/аутсайдер», за счет открытого признания того, что интерпретация происходящего представляет собой неотъемлемую составляющую любой интеракции, включая отношения между исследователем и теми, кого он изучает.

Вот как об этом пишет Дороти Смит, посвятившая свои исследования повседневной жизни женщин: «Я использую... социологический подход инсайдера, т. е. систематическим образом развертывающееся познание общества изнутри, позволяющее избежать конструкции, которая выводит нас за рамки того, вне чего мы не можем существовать. Начиная с реального размещения субъекта, мы возвращаемся к социальному миру, который порождается и познается в контексте актуальных, продолжающихся действий реальных людей. Здесь мышление не противопоставлено практике...[Его формы -] вера, знание, идеология...[сами представляют собой] социально организованную практику, поскольку реализуются в реальных месте и времени с использованием конкретных материальных средств в определенных материальных условиях» [8].

Такая исследовательская позиция «включенного», - а в антропологии «участвующего» - наблюдения открывает предметную область изучения механизмов социального взаимодействия и его культурного содержания, принципиально недоступную на уровне институционального анализа. Прежде всего, в этом случае преодолевается дихотомия объективного/субъективного. И не только потому, что исследователю и изучаемым приходится обмениваться перспективами (по А. Шютцу), чтобы отношения между ними продолжались. Но и потому, что согласно теореме У. Томаса об определении ситуации, если ситуация определяется представителями определенной культуры или субкультуры как реальная, то она реальна по своим последствиям. Далее, в таком контексте можно проследить, действие механизмов, которые обусловливают взаимные переходы или автономию взаимодействия и коммуникации, локально воплощенных акционных и дискурсивных феноменов. Кроме того, вполне доступными наблюдению становятся движения от одной темы или ситуации интеракции к другой. Наконец, исследователю приходится постоянно рефлектировать относительно адекватности своих интерпретаций того, что происходит.
В настоящее время к основоположникам теоретической микросоциологии, которая негласно включала в себя культурное измерение, принято относить таких социологов, как

Ч. Кули (Я-концепция), Дж. Г. Мид (отношения Я-другой), А. Шютц (концепции естественной установки и обмена перспективами в контексте повседневной интеракции), Д. Хоманс и П. Блау, (теория социального обмена), И. Гоффман (теории повседневных личностных презентаций и фреймов интеракции), Г. Гарфинкель (этнометодология). Вплоть до 80-х гг. ХХ в. эти идеи находились на периферии социологического мейнстрима, где доминировали исследования крупномасштабных социальных систем и институциональных структур. Ближе к концу века микросоциология - само название появилось тогда же - стала заметным социальнонаучным направлением, которое все же пока не относится к основополагающим, поскольку находится в стадии становления.

В то же время оно оказало определенное влияние на современную теоретическую социологию. Начиная с феноменологической ориентации (А. Шютц, П. Бергер и Т. Лукман) в научный обиход прочно вошел концепт повседневной реальности, выделяющий в качестве предметной области непосредственные, «здесь-и-сейчас» осуществляющиеся взаимодействия и коммуникации людей. Это дополнило институциональную картину социальной реальности и высветило проблемы, связанные с отношениями между обоими уровнями. Были выделены и зоны таких интеракций, обозначенные как ситуации, фреймы, а также представленные как сценические метафоры И.Гоффмана. Соответственно появилась необходимость внутренней дифференциации этой предметной области, что повлекло за собой более внимательное отношение к концепту социального пространства. Исследователям пришлось обратиться к лингвистическим и семантическим конструкциям. В результате в рамках социологии начала открыто признаваться необходимость серьезного обращения к понятию «культура».

Это направление открыло возможность решать некоторые фундаментальные теоретические задачи изучения социальной динамики, которые обозначились в рамках статичной макросоциологии, но не поддавались детальному рассмотрению в контексте ее предметной области, категориального аппарата, методологии. Так, в философии К. Поп- 
пер, а в социологии Р. Мертон обратили внимание на непреднамеренные последствия рационально организованных действий или событий. Это явление было названо эмердженцией. На уровне макросоциальной системы оно фиксировалось исследователями, и возможность его актуализации признавалась. В то же время это была простая констатация такого рода последствий без объяснения условий, факторов и механизмов их осуществления в контексте социальных действий. Соответственно на теоретическом уровне существенным образом затруднялось построение долгосрочных и среднесрочных прогнозов. Обращение к микроанализу позволяет, по крайней мере, определить те пункты во взаимодействиях и коммуникациях людей, где эмерджентность может изменить установившийся ход событий.

Значимая теоретическая возможность открывается в связи с общераспространенным представлением о вероятностной природе социальной реальности. Даже предпринимались попытки математически определять вероятность выборов и принимаемых решений в ситуациях неопределенности. Это осуществлялось в рамках строго рационалистических моделей, и любые результаты рассматривались как необходимые и оптимальные. Соответственно те, что выходили за заранее установленные пределы, трактовались как ошибки, отклонения, неудачи и т. п. Сравнительно недавно и именно благодаря обращению к микроанализу некоторые исследователи стали использовавать понятие средневековой философии «контингентность». Если в терминах классической логики любое явление социокультурной жизни рассматривается как либо необходимое, либо случайное, то теперь оказывается, что оно может быть ни тем, ни другим. Речь идет о выборах, которые люди совершают применительно к конкретным случаям и из тех наличных возможностей, с использованием тех ресурсов, которыми они располагают в данный момент. Более того, решения в конкретной ситуации не являются обязательными. Соответственно понятие контингентности позволяет выйти за жесткие рамки рационалистической модели и при трактовке устойчивых социальных и культурных образований, при прогнозировании длительности их существования обратиться к неотрефлексированным побуждениям актора, к его опыту, т.е. к культурному измерению активности.
Такая теоретическая позиция меняет представление об изучении социальных порядков. Кроме того, что, как обычно, в определенных ситуациях можно проследить их функцию контроля над взаимодействием и коммуникацией, над сохранением целостности социальных систем, становится доступным другой аспект их рассмотрения - социально-динамическая прагматика. Появляется возможность понять, каким образом временно преодолевается неопределенность ситуации. За счет ее контингентного определения акторы могут примирять свои текущие желания и интересы в контексте конкретных интеракций, интерпретировать эмерджентные последствия событий, вписывая их в принятые интерсубъективные (культурные) рамки.

Следует подчеркнуть, что важной чертой микросоциологии стало обращение ряда теоретиков к идеям лингвистической философии и семантическому анализу событий и явлений общественной жизни. Это оказалось необходимым при поисках ответов на вопросы, которые появились в результате перехода в новое предметное поле. Как упорядочиваются неструктурированные области социальной реальности? Что происходит с социальными и культурными объектами, когда они теряют свою прагматическую значимость? Почему и как появляются новые искусственные образования? Каким образом происходят переходы от одних ситуаций интеракции к другим? Каковы связи между тем, что люди говорят, и их реальными действиями? Каковы механизмы, позволяющие людям считать непрерывными, продолжающимися дискретные во времени социальные взаимодействия и коммуникации? Все эти и подобные вопросы сегодня стали предметом пристального внимания в рамках микросоциологии, оказавшейся под сильным влиянием идей культурной антропологии, постструктурализма, постмодерна.

С. Кравченко так обобщил происходящие перемены: «Усложняющаяся социокультурная динамика изменяет не только социум как совокупность объективных институциональных структур, социальных и культурных типов, ценностей и норм, но и то, как люди, живущие в разных культурах, субъективно конструируют и интерпретируют общество, делая это, естественно, по-разному» [9]. Здесь важно отметить акцент автора не только на динамическом аспекте сложной современной социальной жизни, но и на ее культурном измерении. Изучение этих аспектов совместно- 
го существования людей предполагает разработку специального теоретического и методологического инструментария.

\section{Предметное поле социологии культуры в свете идей постмодерна.}

В соответствии с теми изменениями в области социологии, которые были отмечены выше, можно конкретизировать основные теоретические положения, которые существенным образом повлияли на содержание предметного поля социологии культуры как ее формирующейся отрасли, в том числе на ее сближение с культурной антропологией. В этом контексте существенным образом изменилось представление о связях между социальной структурой и культурой, о динамике того, что стало называться социокультурной реальностью. Практически перестали говорить об историческом процессе как непрерывной «цепи бытия», в какой бы форме - эволюционной или волнообразной - она ни представлялась. Применительно к социокультурной жизни изменчивость мыслится, скорее, как совокупность дифференциальных процессов, происходящих на разных уровнях и не сводимых друг к другу. Одни из них можно представить как непрерывные и длительные, другие - как дискретные и краткосрочные; одни соотносятся с цикличностью, другие с необратимостью. Что касается социокультурных образований, то одни из них трактуются как системы в классическом понимании, а другие - как своего рода конгломераты. Относительно первых считается, что их равновесные состояния сменяются структурными трансформациями, а периоды внутренней консолидации сменяются возрастанием функциональной автономности их составляющих. Для изучения порождения и динамики вторых пока не сложились удовлетворительные теоретические модели.

Однако признается изменчивая природа социокультурной реальности, которая характеризуется тем, что в этом поле возникают и разрушаются как устойчивые, так и нестабильные, как внутренне взаимосвязанные, так и неупорядоченные образования. Подвижное существование несистемных объектов связывается с их открытостью, незавершенностью, интенсивным информационным (в общенаучном смысле) обменом с окружением. Предполагается, что, несмотря на отсутствие внутренней упорядоченности и гомеостатических связей с окружением, они не обяза- тельно разрушаются, но существуют в режиме постоянных преобразований конфигурации и изменений траектории движения. Раньше в социологии ими никто не интересовался. Теперь этот доструктурный слой социокультурной реальности, который можно описать через понятие протоморфов (аналитических единиц, характеризующих уже не поле, но еще не структуру) постепенно становится предметом теоретизирования. И хотя системные, структурно-функциональные представления продолжают доминировать в рамках социологического мейнстрима, микроизменчивость становится той предметной областью, которая позволит ответить на вопросы, поставленные выше.

Именно такая позиция вырисовывается из анализа работ тех социологов, которых принято относить к выразителям идеологии постмодерна. Это интеллектуальное течение связывается с существенным пересмотром познавательных принципов, характерных для западной культуры в период с конца XIX до середины XX вв. - эпохи модерна. Оно сложилось на взаимоналожении таких направлений этого культурного стиля, как авангард, конструктивизм, структурализм. Его специфика определяется исключительным вниманием к движению, неопределенности, переходности.

Первоначально ориентации такого рода наиболее отчетливо воплотились в сфере искусства. Их влияние сказалось на идеях прежде всего философов, антропологов и в меньшей степени социологов. Швейцарский исследователь М. Франк предложил для этого мировоззрения название «неоструктурализм» и полагал, что оно сложилось к 1968 г. [10] Другие считают, что оно сформировалось к 1975-1976 гг. и объединило теоретические направления, носившие названия «постструктурализма», «неоструктурализма», «исторического номинализма» и др. Соответственно отмечается возникновение особого «гибридного поля», включившего в себя элементы социологической теории, литературоведения, философии и теории культуры [11] К середине 1970-х гг. постмодернизм как культурное течение широко распространяется в Европе и Америке. К началу 1980-х гг. понятие «постмодерн» приобретает законное место в культурной антропологии и социологии, а $\Phi$. Джеймиссон и Ж.Ф. Лиотар вообще назвали условия современной жизни постмодернистскими. Соответствующие явления стали предметом особенно оживленных дискуссий 
среди интеллектуалов во всем мире в течение 1980-х гг. Со временем откристаллизовалось представление об этой идеологии как о совокупности «экспериментальных тенденций в современной западной культуре, которая во многом ассоциируется с понятием постиндустриального общества» [12]. С ней устойчиво связываются такие имена, как Ж. Деррида, Ж.Ф. Лиотар, Ж. Делез (философия), М. Фуко, Х. Уайт (история), Ж.Лакан, Р. Лэнг, Н.Браун (психоанализ), Г. Маркузе, Ж. Бодрийар, Ю.Хабермас (политическая философия), Т. Кун, П. Фейерабенд (философия науки), Р. Барт, Ю. Кристева, В. Изер, «Йельские критики» (теория литературы), Э. Гоулднер, И. Гоффман, Г. Гарфинкель (социология). Постмодерн стали рассматривать как интернациональное стилистическое направление в культуре. Истоки его основных формообразующих принципов принято искать в рамках европейского экзистенциализма, особенно в работах М.Хайдеггера; основоположниками движения называют европейцев Ж. - П. Сартра, С. Беккета, Э. Ионеско, Ж. Жане, М. Фриша, Н. Саррот и др. Выразитель эстетических идей постмодерна писатель и семиолог У. Эко говорит о нем как о метаисторической категории, сменившей предшествующие - «модернизм», «авангард», - когда они исчерпали свой эвристический потенциал и происходит разрушение ранее сложившейся образной парадигмы. «Ответ постмодернизма модернизму состоит в признании прошлого: раз его нельзя разрушить - ведь тогда мы доходим до полного молчания - его нужно пересмотреть иронично, без наивности» [13].

Обобщая признанные характеристики этого интеллектуального течения, один из известных его последователей пишет: «Ситуация постмодерна характеризуется тем, что мы противостоим возрастающему многообразию самых различных форм жизни, концепций знания, способов ориентации, что мы обнаружили законность и неоспоримость такой плюральности и безоговорочно все более признаем и оцениваем ее... В этом многообразии и в согласии с ним находится фокус постмодерна». Дело не только в осознании неустранимости сосуществования разнородных культурных идентичностей и самоидентификаций. «Значительно важнее то, что речь идет о признании множественности принципов и ритмов самоорганизации социокультурной жизни. Плюральность постмодерна - это указание на субстанциональную множественность, присущую культуре, пронизывающую ее снизу доверху» [14].

Все эти изменения в философском и социально-научном дискурсе способствовали формированию новой модификации социологии культуры как области теоретического познания. Д. Крейн подчеркивает, что с начала 1970-х гг. она фактически стала «заново изобретаться», «но в ранние девяностые масштабы ее трансформации начинают признаваться остальными представителями дисциплины. 'Новая' социология культуры - это не познавательная ветвь per se; скорее, она состоит из ряда отдельных и независимых друг от друга предметных областей, таких как наука, познание, религия, масс-медиа, популярная культура, искусство, а также культурно ориентированных подходов, например, к истории, политике, организациям, стратификации, межличностному поведению» [15]. Такая полистилистика скрепляется исходным допущением об относительной автономности динамики символических систем от событий социально-структурного порядка и акцентом на содержании совместного существования людей, семантике социокультурной реальности.

В дискуссиях о современной социологии культуры можно обнаружить две позиции. Одна из них относится к месту категории культуры в предметной области социологии. Представители мейнстрима полагают, что при изучении соответствующих явлений и процессов достаточно применять социологические методы. Это наиболее распространенное, но не эвристичное представление. Те же, кто признает необходимость смены познавательной парадигмы, предлагают систему координат, где культурное измерение равнозначно по отношению к социальному, как концептуальные рамки для интерпретации событий, происходящих в совместной жизни людей.

Сторонники такой позиции, пока немногочисленные, исходят из теоретических предпосылок, сложившихся в период постмодерна, и ориентируются на изучение социокультурной микродинамики, сравнительно недавно ставшей предметом исследовательского внимания. Другая позиция связана с определением времени возникновения социологии культуры. Сегодня нередко встречаются утверждения, что она существует с момента возникновения социологии как самостоятельной науки, и к ее представителям относят М. Вебера, Э. Дюркгейма, Г. Зиммеля, Б. Малиновского, Дж. Г.Мида, А. Рэдклифф-Брауна. Эта точка 
зрения базируется на том, что в период раннего модерна основоположники еще только становящейся социальной науки затрагивали вопросы, которые сейчас относятся к области изучения культуры. Однако ни один из них не только не создал соответствующей целостной теории, но и не раскрыл познавательный смысл этого понятия.

Одним из первых, кто в середине 1940-х гг. поставил вопрос о необходимости такого направления в социологии, был К. Манхейм. Он предложил теоретическую программу его построения, где синкретически присутствовали обе позиции, о которых говорилось выше. Однако в то время и позже у него не оказалось последователей. Его идеи стали актуальными тогда, когда, по словам Д. Крейн, социология культуры была «заново изобретена», т. е. фактически в 1990-е гг.

\section{Теоретические предпосылки формирования социологии культуры.}

Определение исходных теоретических допущений современной социологии культуры предполагает обращение к классическим работам, с одной стороны, и идеям постмодерна - с другой [16]. Анализируя работы классиков социологии, Л.Г. Ионин выделяет основные теоретические направления, где представления о явлениях, которые принято относить к понятию культуры, выражены наиболее отчетливо. В этих рамках он рассматривает те идеи, которые до сих пор не утратили актуальности и так или иначе используются современными социологами культуры.

Объективизм. К этому направлению автор относит Э. Дюркгейма, который уподоблял социологию естественным наукам и полагал, что социальные факты, порождаемые на уровне сознания, следует трактовать внешние по отношению к людям и образующие в обществе особую составляющую. Несмотря на свои истоки они не произвольны и не индивидуализированы, но определяются как коллективные представления (термин Э. Дюркгейма). Объективные по своей сути, они рассматриваются функционально обязательные и принудительные. Этот концепт придает культурные коннотации таким понятиям, которыми социология обязана Дюркгейму, как социальная солидарность, аномия, а также его идеям об общественном происхождении морали и религии. В контексте данной статьи важно отметить два важных аспекта этой теоретической позиции: разделение коллективных действий и коллективных представлений, а также детерминирующая значимость последних по отношению к индивидуальной активности сознания.

Понимающая социология. Это направление социологической мысли связывается с именем М.Вебера. Основания его представлений о культуре можно вывести из предложенного им понятия социального действия, которому приписываются следующие атрибуты:

- рациональность - каждое из них побуждается осмысленным намерением (интенцией) и отрефлексированной целью;

- осмысленность - каждый индивид, совершая действие, связывает с ним субъективный смысл;

- совместность - в своей активности люди соотносятся с действиями друг друга и ориентируются на них, что обусловливает возможность взаимного понимания.

М. Вебер исходил из того, что действия можно считать эмпирическими фактами в их реальной среде, а поскольку они совершаются сознательно, посредником между ними и окружением становятся субъективный смысл, интерпретация, обеспечивающие понимание происходящего. В отличие от Дюркгейма, исходившего из допущения, что коллективные представления объективны, Вебер старался объяснить, как это качество формируется из субъективно побуждаемых действий и как их результаты образуют искусственный, созданный людьми мир, который можно назвать культурой общества. Соответственно предметом социологического исследования становится многообразие идей, мнений, убеждений, представлений, образов мира. Из основанных на них рациональных действий, согласно Веберу, складываются социальные отношения, которые он характеризует как «поведение нескольких людей, каждый из которых соотносит свои действия с действиями остальных и ориентируется на эту соотнесенность» [17]. Они могут различаться по содержанию, форме, времени существования, месту реализации, но универсальным образом базируются на принципах рациональности и взаимного понимания людей. При длительном воспроизведении взаимная соотнесенность действий, т.е. структура связей между ними стандартизуется и приобретает своеобразную независимость от конкретных акторов, т. е. объективность. 
Итак, искусственные образования порождаются рациональной, имеющей субъективный смысл активностью людей. При повторяющейся взаимной соотнесенности в совокупности такие действия образуют социальные отношения. Последние при необходимости и длительности воспроизведения приобретают характер объективных.

Символический интеракционизм. Символический интеракционизм как культурно ориентированное социологическое направление, отмечает Л.Г. Ионин, основывается по крайней мере на двух предшествующих теоретических предпосылках. С одной стороны, - концепция социальности Ч. Кули, понимавшего ее как комплекс чувств, предрасположений, моральных норм, формирующихся в непосредственных отношениях людей и составляющих идеальную среду их действий. С этой точки зрения, возможность совместной активности обеспечивалась тем, что ее внешние проявления считались обусловленными сознанием. С другой стороны, - гипотеза об «определении ситуации», Р. названная Мертоном «теоремой У.Томаса», которая гласит: «если ситуация определяется как реальная, она реальна по своим последствиям». Соответственно предполагается, что совместная активность людей и условия ее реализации не объективно заданы, но детерминированы их восприятиями и представлениями.

Эти исходные допущения составили основу теоретических построений основоположника символического интеракционизма Дж. Г. Мида. Он полагал, что общество и индивидуальное сознание формируются и поддерживаются в процессах взаимодействий (интеракций) людей благодаря работе определенного трансформационного механизма. Идеям, составляющим содержание сознания, соответствуют внешние «жесты», символы, репрезентирующие представления, выражаемые в вербальной форме как слова. $\mathrm{C}$ их внешнего проявления начинается интеракция. В качестве стимулов они вызывают стандартные реакции участников совместной активности, поскольку символы актуализуют в их сознании одну и ту же «идею», которая считается их значениями.

Действие этого механизма, согласно Миду, обеспечивает «принятие роли другого», т. е. освоение и использование «жестов», проявляемых в поведении окружающих. При многочисленных и разнородных взаимодействиях у каждого формируется представление, что окружающие отличаются от него самого. Мид пишет об этом так: «Действительная универсальность и безличность мысли и разума является результатом принятия индивидом установок других людей по отношению к себе и последующей кристаллизации этих частных установок в единую установку или точку зрения, которая может быть названа установкой обобщенного другого» [18].

Таким образом, Мид не только обозначил механизм, действие которого обеспечивает возможность интеракции, т. е. обусловленности действий одного актора «жестами» другого. Он также вывел из этого способ выражения «универсальности и безличности» социальных структур в процессах символических интеракций. Иными словами, в неявном виде он допустил наличие интерсубъективного пространства, где в процессах взаимодействий «жесты» обретают значения.

Феноменологическая социология. Тема преобразования «субъективности» множества индивидуальностей в «объективную» социальную реальность стала ключевой в рамках так называемой феноменологической социологии. Ее основоположник - австрийский философ и социолог А. Шюц интерпретировал идеи понимающей социологии М. Вебера с позиции феноменологии Э. Гуссерля в его поздней трактовке социального мира. В этих теоретических рамках предметной областью изучения становится интерсубъективная реальность, порождаемая совместной активностью людей и составляющая контекст их самоопределения в различных ситуациях взаимодействия. В соответствии с исходными допущениями феноменологии она считается результатом преобразований людьми своих связей с окружением на уровнях сознания и бессознательного, т. е. представлениями о них. В таком качестве человек принимает ее безоговорочно как непосредственно данную, субъективно ощущает как достоверную.

Этот «жизненный мир», согласно А. Шютцу, не следует понимать как нечто синкретичное, нерасчлененное. Он объективируется и упорядочивается людьми в процессах необходимого взаимодействия друг с другом и искусственными объектами, среди которых они живут. Соответственно задачей социолога становится изучение становления «социальной объективности, начиная с элементарнейших процессов конституирования, порождения смыслов в «потоке опыта», затем «значимых действий», обладающих субъективным 
смыслом (в духе Вебера) и так далее вплоть до конституирования объективных социальных структур во взаимодействии индивидов» [19]. Совершенно очевидно, что здесь присутствует, хотя и не акцентируется, культурное измерение социальной реальности.

В дальнейшем эти основополагающие идеи были разработаны и уточнены в рамках социального конструктивизма П. Бергера и Т. Лукмана, этнометодологии Г. Гарфинкеля, когнитивной социологии А. Сикурела, а также новых версий символического интеракционизма (Г. Блумер). Предметной областью изучения по-прежнему остается существование людей в их непосредственном окружении, в контексте межличностных взаимодействий, что обозначается как «повседневная», «обыденная» реальность. Она противопоставляется социетально-институциональной «системе» в ее структурно-функциональной трактовке. И хотя признается, что между ними существует взаимозависимость, однако до сих пор каждый из уровней рассмотрения совместного существования людей представлен своим теоретическим течением. Одно с другим концептуально слабо связаны, поскольку базируются на кажущихся несопоставимыми исходных допущениях - феноменологических в первом случае и общесистемных - во втором.

\section{Задачи социологии культуры и теоретические предпосылки ее современного становления}

Исходя из определения социологии культуры как науки, изучающей «основополагающий феномен культуры» с использованием социологических понятий, К.Манхейм сформулировал ее задачи еще в 1940-х гг. [20]. С тех пор, несмотря на терминологические расхождения, представление об их общем содержании мало изменилось, и считается, что следует изучать:

- как «общественно-историческая реальность» (Дильтей) влияет на формирование культурных образований и отображается в их внутренней структуре;

- как эти образования самим фактом своего существования влияют на динамику форм общественной жизни;

- в какой степени и каким образом они становятся социально приемлемыми и разделяемыми.

Таким образом, предметную область этого научного направления составляют социаль- ные аспекты порождения культурных феноменов, понимаемых как идеальные, и их влияние на конституирование совместного существования людей. В таком концептуальном контексте появляется необходимость методологической рефлексии, оправдывающей выделение социологии культуры в особую область познания. Манхейм утверждал, что ее объекты доступны научному анализу, только если зафиксированы в соответствующих понятиях, между которыми и феноменологически понимаемой «реальностью» нет непосредственной связи, «наподобие копии». Их содержание определяется теоретическими взаимосвязями, благодаря которым они образуются. Из этого следует, что метод исследования позволяет извлечь из феноменов ровно столько, сколько определяется точным формулированием проблем изучения в системе релевантных им научных понятий. Соответственно о достоверности получаемого знания, с точки зрения Манхейма, можно судить по двум критериям: «по степени...дотеоретической чувствительности в отношении подлежащих рассмотрению феноменов, а также по состоянию понятийной систематики, которая в свою очередь имеет собственные логические законы развития» [21].

Все это свидетельствует о том, что социологии культуры нужен свой инструментарий. Прежде всего, необходимо построить отвечающее ее целям определение культуры. Далее, следует отрефлексировать, как меняется понятийный аппарат в связи с выделением особой предметной области, т. е разработать соответствующую социологическую терминологию. Наконец, важно отдать себе отчет в том, что фундаментальной наукой социология остается до тех пор, пока речь идет об изучении общества; в рамках же социологии культуры она становится методом для изучения феномена, до известной степени автономного от нее.

В дальнейшем представления Манхейма о социологии культуры оказались актуальными и были развернуты в рамках постмодернистских направлений.

Если исходить из современной трактовки понятия культуры как искусственного мира людей, составляющие которого имеют определенные значения и смыслы, то из сказанного следует, что эта тема так или иначе затрагивалась в рамках некоторых социологических течений. Более того, даже в пределах общераспространенной концепции социальной си- 
стемы (с ее акцентом на институциональной структуре общества) использование таких понятий, как нормы, ценности, мотивации и т.п., указывают на обращение к культурным, а не только социальным фактам. Это обстоятельство позволило Дж. Александеру выделить набор «неоклассических» теоретических ориентаций, которые в разных композициях окрашивают современные дискуссии вокруг социологии культуры, разворачивающиеся вокруг двух тем. Во-первых, соотношение понятий «общество» и «культура»: каковы степени взаимозависимости и автономности «культуры» и «социальной структуры». Вовторых, содержание категории культуры: каковы ее ключевые составляющие и как они связаны друг с другом. Ответы зависят от теоретических позиций, занимаемых участниками обсуждений. Александер подчеркивает, что "хотя каждый из этих неоклассических подходов формулирует принципы культурного анализа в духе своего основателя, то, как именно данный подход отклоняется от ортодоксальной точки зрения, столь же важно, как и то, как он ее развивает» [22].

«Веберианство». Вклад Вебера в теоретическое осмысление культуры, согласно Александеру, обсуждается в связи с его работой, посвященной протестантской этике. Вопрос заключается не только в том, действительно ли она составляет необходимую предпосылку современного западного капитализма, но ставится значительно шире. Интерпретация идей Вебера выходит за ранее сложившиеся рамки институциональной трактовки структурных связей между ценностями и включает в себя составляемые ими символические системы. Культура здесь рассматривается как производная, можно сказать, антропологически универсального императива формировать и поддерживать связи с трансцендентным. Совокупность их значений и смыслов образует особое метафизическое пространство. Александер отмечает, что «изучение религиозных идей, теологических концепций спасения и фундаментальной роли противоположных путей спасения, определяемых аскетической и мистической схемами, остаются наиболее явными аспектами веберианской теории культуры» [23].

В настоящее время эти феномены выводятся за пределы только религиозной области социокультурного пространства. Им придается статус фундаментальных представлений о социальном и индивидуальном, о побуждениях к активному преобразованию окру- жения, о сознании вообще, что меняет ранее принятую трактовку социальных институтов. Помимо социально значимых функций центром внимания становятся их символические составляющие, репрезентирующие соотношение формальных и неформальных институциональных связей, политического контроля и частной жизни, внутригрупповых и межгрупповых идентификаций. Александер считает это направление социологии культуры исторически и социально ориентированным и наиболее близким к семиотике, поскольку здесь особое внимание уделяется изучению внутренней логики символических систем.

«Дюркгеймианство». Как и в предыдущем случае, в рассуждениях о культуре религия остается основной предметной областью. В ее рамках центром внимания становятся сложность символических систем, их автономность и зависимость по отношению к социальным структурам, социальные референции их отдельных составляющих. Однако для этого теоретического направления - в сравнении с веберианским - не характерно обращение к историческому сравнению специфики различных этических систем. Здесь интерес фокусируется на устойчивых структурных составляющих социально значимых символических систем, на культурных универсалиях, независимых от исторической и локальной специфики их актуализации. По мнению Александера, такая трактовка культуры близка к структуралистской, поскольку влияние Дюркгейма испытали и $Ф$. де Соссюр, и М. Мосс, которого К. Леви-Стросс назвал основоположником структурной антропологии.

В дюркгеймовских представлениях о культуре сегодня принято подчеркивать значимость бинарных оппозиций. Однако эта конструкция отличается от той, что предложена в рамках структурализма Леви-Стросса. Она предстает не просто как проявление антропологически универсальных способностей к разделению природных и культурных объектов и их классификациям. Подразумевается, что такое противопоставление отличается интенсивной эмоциональной и моральной окраской, относящейся к различению сакрального и профанного. Эти компоненты помогают поддерживать солидарность и идентичность в сообществах благодаря ритуалу. Считается, что эта культурная форма одухотворяет и эмоционально наполняет сакральные символы, относящиеся к угрозам для личности или для социальной солидарности 
Марксизм. Александер считает наиболее значимой фигурой, представляющей марксистскую трактовку культуры, А. Грамши, который исходит из допущения, что это производная «реальной силы» общества - социальной системы. Культурные процессы, понимаемые как движение идей, не осуществляются автономно, но связаны с институтами и сопровождают либо поддержание, либо изменение их.

Грамши опирается на концепцию стратифицированных, социально иерархизированных обществ, где доминирующий способ производства и классовое господство поддерживаются политическими силами. Культурные характеристики правящего класса становятся образцом для общества в целом. Те же, кто создает культурные инновации и пытается сохранять автономность мировоззрения, - интеллектуалы - из-за слабой институциональной позиции вынуждены примиряться с такой ситуацией. Им приходится в символической форме репрезентировать «самопонимание» наличной социально-политической системы. Эти представления в упрощенной форме транслируются наемными работниками через институты образования и массовых коммуникаций. Таким образом, интеллектуалы оказываются проводниками идеологии капитализма.

Итак, в иерархии капиталистического общества правящий класс поддерживается не только силовыми структурами, но и с помощью мировоззрения. Согласно Грамши, носители власти стараются институционально обеспечить приверженность членов общества соответствующим идеям, чтобы она стала частью их социализации и имела вид добровольной. Привлеченные к решению этой задачи интеллектуалы добровольно или по принуждению работают на сохранение идеологического господства, или «культурной гегемонии» по отношению к «массам». Так культурными средствами поддерживается доминирующий социальный - в первую очередь «морально-политический», а потом уже политико-экономический - порядок.

Однако Грамши полагает, что на смену доминирующим культурным ценностям неизбежно приходят новые. Но и в этом случае таким изменениям предшествует трансформация «реальных обстоятельств». С этой точки зрения трактуется положение в обществе и культуре рабочего класса, объекта эксплуатации, реализующего практическую деятель- ность. На нее в первую очередь ориентировано сознание его представителей, и потому они не готовы к противостоянию господствующей идеологии аристократии или буржуазии. Тем не менее, накопление недовольства среди «эксплуатируемых масс» порождает необходимость в альтернативной системе ценностей. Она формируется (по Грамши, как социалистическая) интеллектуалами, маргинальными по отношению к господствующему (капиталистическому) режиму и ориентирована на практику в большей степени, чем на доминирующие идеалистические доктрины. Составляющие ее идеи эмпиричны и широко доступны.

Без сомнения, это нормативная трактовка культуры. Речь идет не столько об объяснении фактов, сколько об их интерпретации, о различении их смыслов в терминах добра и зла. «Его [Грамши] целью является не просто объяснить, как может развиться контргегемоническая культура, но и показать, что она может привести и приведет к тому, что он считает более свободной и независимой жизнью» [24].

Итак, в рамках этой концепции культура оказывается неизбежно локализованной в социальном пространстве, которое трактуется с классовых (в марксистском понимании) позиций.

Структурный функционализм. Принято считать, что каноническая институциональная трактовка культуры в рамках этого теоретического направления принадлежит Т. Парсонсу. Он придавал особую важность ее включенности в структуры социальных систем. По его мнению, задачам социологии (характерной для его времени) наиболее соответствует именно этот акцент, при котором основное внимание уделяется не символическим системам как таковым а «ценностям». Последние понимаются как символические абстрактные полюсы культурных эталонов, с которыми следует соотноситься при обсуждении основных институциональных проблем. Обычно выделяются такие оценочные шкалы, как равенство-неравенство, спонтанность-дисциплина, авторитет-критика власти, общественная-частная собственность. Согласно Парсонсу, именно в соответствии с ними акторы делают выбор между реальными альтернативами. Институционализация таких культурных категорий предполагает их включенность в определенные функциональные роли таким образом, что следование им (индивидуальное 
или коллективное) поощряется, а пренебрежение ими - осуждается. В результате вокруг этих оценочных шкал, считает Парсонс, формируются институциональные нормы.

Таким образом, акцентируется специфично институциональный аспект культуры. Однако им не исчерпываются даже процессы, происходящие в рамках формальных организаций, поскольку здесь наряду с официальными функциональными связями неизбежно существуют и межличностные отношения. Их следует рассматривать в терминах «культуры повседневности». Однако с помощью концепции Парсонса описывается лишь та ее часть, которая ограничивается областью морали.

Постструктурализм. По мнению Александера, это интеллектуальное течение повлияло на переинтерпретацию основополагающих идей классиков модерна. Считается, что оно зародилось в конце 1960-х гг. на пересечении критических идей (нео)марксизма, с одной стороны, и теоретических ориентаций семиотики и структурализма - с другой. Сейчас оно существенным образом отличается от истоков, что, например, отчетливо проявляется в работах таких авторов, как М. Фуко и П. Бурдье. Оба вышли за пределы радикального структурализма с его трактовкой культуры как текста, который следует интерпретировать в терминах его самого (герменевтически). Они признавали связь символизации с социальными классами и властными структурами. Однако расширили рамки структурно-функциональной концепции социальной системы, подчеркивая, что ее структурные составляющие имеют определенные значения и смыслы. Предполагается, что для объяснения устойчивости и изменчивости стратификационных компонент и институциональных организаций недостаточно выявить их строение. Необходимо принимать во внимание, что осуществляемая здесь совместная активность детерминируется характерными для них как внутренней формой, так и культурными кодами.

В рамках постструктурализма предпринимаются попытки установить логические связи между структурным функционализмом с его преимущественным акцентом на формальных характеристиках социальных систем и семиотикой (семантикой), где в центре внимания находятся значения и смыслы отношений между людьми и их окружением. Соответственно считается, что «Социальный мир не предстает как полно- стью структурированный и способный навязать любому воспринимающему субъекту прототипы собственной конструкции. Социальный мир может быть назван и построен различным образом в соответствии с различными принципами видения и деления: например, деления экономического или деления этнического... сила экономических и социальных различий никогда не бывает такой, что невозможно организовать агентов в соответствии с другими принципами деления» Таким образом, «восприятие социального мира есть продукт двойного структурирования. Со стороны объективной оно социально сконструировано, поскольку свойства, атрибутированные агентам или институциям, предстают в сочетаниях, имеющих очень неравную вероятность.... Со стороны субъективной оно структурировано в силу того, что схемы восприятия и оценивания, в особенности те, что вписаны в язык, выражают состояние отношений с символической властью» [25]. Иными словами, необходимо теоретически объединить формы и содержание общественной жизни, что возможно с помощью понятия культурных кодов.

\section{Сближение социологии и антропологии}

На современной стадии формирования социологии культуры необходимым оказалось обращение к антропологическим теоретическим идеям. В свое время по известным интеллектуальным причинам - разграничение предметных областей, объектов исследования, концептуальных ориентаций - социология и антропология из первоначального синкретизма выделились в отдельные науки и учебные дисциплины. В то же время между ними никогда не было непроницаемых границ. Так, теория социальной стратификации, широко распространенная в социологии, была разработана антропологами. А концепция эволюционных универсалий, которые в силу их искусственного происхождения можно считать культурными феноменами, принадлежит социологу - Т. Парсонсу. Вместе с тем вплоть до сравнительно недавнего времени вопрос о научной значимости теоретической схемы, объединяющей социологическое и антропологическое знание, прямо не ставился. Сейчас такая необходимость не вызывает сомнений, хотя и признается, что преодоление различий между обеими науками вызывает 
целый ряд затруднений. Поиски в этом отношении свидетельствуют о том, что такой синтез вполне достижим с помощью определенных познавательных приемов.

Обращение к антропологическим универсалиям. Эту тему можно считать одной из центральных антропологии на протяжении всего ее существования. В рамках социологии культуры, в контексте принятой здесь трактовки символической реальности она представлена структуралистской формой. Начиная со структурной антропологии К. ЛевиСтросса, сложилась устойчивая ориентация на выявление трансформационных механизмов, изначально присущих человеку, которые придают определенность его отношениям с окружением и находят выражение в культурно универсальных символических формах. Для социологии культуры эта теоретическая позиция имеет большое значение. $\mathrm{C}$ ее помощью можно обратиться к контекстам социально обусловленного продуцирования значений и смыслов, относящихся к устойчивым связям между людьми, к институтам, а также к взаимной автономности социальных структур и культурных образований.

Было признано, что совместная активность людей во многом определяется неосознаваемыми «глубинными структурами отношений», которые порождают социальную реальность как таковую. Она приобретает знаково-символическую репрезентацию, составляющую собственное пространство со своим строением. Иными словами, предполагается, что закономерности взаимодействия и символической коммуникации различаются между собой. Социальные связи принято характеризовать устойчивостью и повторяемостью, обеспечивающими экономию энергии в совместной активности людей, направленной на удовлетворение их базовых потребностей, с одной стороны, и поддержание значимых для них систем взаимодействия - с другой. Семантические же единицы трактуются как открытые формы, меняющие значение в зависимости от интерпретации содержания интеракционных ситуаций, которые обусловливаются социальными императивами.

Таким образом, теоретический «зазор» между универсальными антропологическими свойствами социальности и символизации открывает в рамках социологии культуры особую предметную область их взаимосвязей и относительной независимости друг от друга. Дальнейшие постструктуралистскоие иссле- дования Р. Барта, Ж. Деррида, М. Фуко и др. породили для ее теоретической дифференциации целый ряд новых понятий, таких как «письмо», «культурный код», «дискурсивные практики», «эпистема», «архив», «археология знания», и их производных. Этот тезаурус, хотя и далеко не завершенный, задает отрефлексированное представление о социальной реальности как о социокультурной.

Влияние «этнонаучных» представлений. В рамках социологии культуры начали уделять внимание особому ответвлению структурализма, обозначаемому в антропологии как этнонаука. Здесь изучаются так называемые «естественные» классификаци (символически упорядоченные области социокультурной реальности) и парадигмы (правила поведения и взаимодействия в пределах таких порядков). Они нерефлексивно формируются и используются в контексте непосредственных обыденных (повседневных) интеракций и играют важную конституирующую роль в совместном существовании людей. Эти образования отличаются от социетально-институциональных, которые в рамках социологии мейнстрима трактуются как рациональные и интенциональные.

Однако, по словам П. Бурдье, объективистски понимаемая социальная реальность на самом деле воспринимается и структурируется людьми по-разному, что со всей очевидностью продемонстрировали этнометодологи. Он полагает, что к предметной области социологии культуры наряду с объективированными ее составляющими следует присоединить и представления об их смыслах и значениях у людей, занимающих различные позиции в социальном пространстве. По его мнению, наступило время «пойти на разрыв с объективизмом, введя в поле анализа элементы, которые ранее при построении концепции социальной реальности не принимались во внимание. Речь идет о социологии восприятия социальной реальности, т.е. о социологии формирования мировоззрений, способствующих, в свою очередь, конструированию социальной реальности. Но, учитывая, что социальное пространство сконструировано нами, мы понимаем, что любая точка зрения, как показывает само это словосочетание, - это взгляд с определенной точки, то есть с определенной позиции, в рамках социального пространства» [26].

Влияние интерпретативной антропологии. В рамках современной социологии куль- 
туры заметным становится влияние интерпретативной антропологии К.Гиртца, который сам почерпнул социальные предпосылки своей широко известной работы «Интерпретация культур» из теории Т. Парсонса. Он рассматривает культуру как сложный многомерный текст, который не только обусловлен социальностью, но и влияет на ее формы и динамику. Отношения между этими аспектами совместного существования людей, по его мнению, трудно уловимы, поскольку четко не фиксированы и зачастую скрыты от наблюдения. Однако они находят отображение в культурной реальности, которая, понимаемая как текст, может быть прочитана и интерпретируется людьми, придающими смысл собственному окружению.

Гиртц предлагает также своего рода герменевтическое прочтение чужой культуры, используя характерное для так называемой новой этнографии «подробное описание», записи, которые делает антрополог в ходе участвующего наблюдения. Эта техника отличается от принятых ранее, предполагающих максимальное дистанцирование исследователя от изучаемых событий. Здесь речь идет не только об описывании наблюдаемого в двух перспективах - своей собственной и информантов, но и о подробном фиксировании контекста происходящего, собственного участия в ситуации, своих переживаний и соображений по поводу разных ее аспектов. При такой рефлексивной позиции, считает Гиртц, антрополог может обнаружить и связи между взаимодействием и коммуникацией, и значения слов и жестов информантов, и смыслы взаимных реакций.

Эту герменевтическую позицию Гиртца разделяет основоположник так называемой «сильной» программы культурной социологии Дж. Александер, полагающий, что она обеспечивает возможность прочтения культуры как текста. Отправной точкой в этом случае становятся принятые здесь знаки и символы, смыслы которых, согласно Леви-Строссу, представляют собой производные от знаковой системы, а не от социальной структуры и, следовательно, относительно автономны от нее.

Представление о том, что знаковые и символические порядки составляют текст культуры, позволяет рассматривать ее как совокупность различных форм нарративов - моральная пьеса, мелодрама, комедия, трагедия и т. п. Такая концептуализация, по мнению Александера, становится связующим звеном между герменевтической позицией Гиртца и его собственной. В этом случае любой культурный текст соотносится с нарративами, характерными для социальных институтов, задающих им определенные смыслы.

В свое время еще К. Манхейм писал: «Для того, чтобы вообще могла возникнуть социология культуры, была необходима новая точка зрения, новая концепция произведений духа, которую принято называть генетической, и в качестве ее специальной разновидности - концепция социогенетическая» [27]. В то же время Александер подчеркивает, что институты, процессы и акторов следует рассматривать в качестве причинных посредников, а не первопричин смыслов производимых ими культурных текстов. Таким образом, социетальноинституциональное пространство становится аналитической областью, где оказывается возможным объединить условия социальных интеракций, участвующие в них социальные силы и используемые здесь культурные коды.

\section{Заключение: познавательная значимость социологии культуры}

Из всего сказанного следует, что формирование социологии культуры как самостоятельной области исследования базируется на серьезных теоретических предпосылках и обусловлено осмыслением общепризнанных проблем, которые

не могут быть решены с помощью прежних познавательных моделей. Основной темой становится изучение социальной реальности с точки зрения изменчивости, ее движущих сил, механизмов, упорядоченности и т. п. Для этого теории социологического мейнстрима оказались недостаточными. Во-первых, тенденции сводить описание социальных явлений к экономическому и политическому измерениям оставили вне сферы внимания другие аспекты совместного существования людей, оказывающие влияние на динамику социальных структур. Для их интерпретации оказалось необходимым наряду с институциональным анализом обратиться к более подробному изучению повседневной реальности, т. е. помимо макрсоциологических теорий начать формировать микросоциологические. В этом случае обращение к понятию культуры стало необходимым. Во-вторых, на микроуровне в сферу исследовательского внимания попадают не только структурные, - как прежде, - но и содержательные аспекты со- 
циальной реальности, взаимное влияние и относительная автономность символических и структурно-функциональных систем, вариации взаимодействий и коммуникаций как область порождения социальных и культурных изменений. Пока социология культуры как теоретическое направление находится в стадии становления, ее немногочисленные версии разрознены, а их адепты нередко конкурируют друг с другом. В то же время уже сейчас можно в самом общем виде выделить ее основания и границы.

Первоначально в отечественных словарях социология культуры определялась как область социологии, где изучаются аспекты общественной жизни, влияющие на «производство, распространение, хранение и потребление культурных ценностей», т.е. преимущественно их функционирование. Это стандартное клише было вполне приемлемым, пока исследования ограничивались подсчетом посещений развлекательных учреждений и предпочтений в области искусства. Оно удовлетворяло и теоретиков, которые прежде занимались социологией знания, искусства, религии, идеологии. В их задачу входило не изучение значений и смыслов искусственных образований (артефактов, объектов культуры) в контексте совместного существования людей, но их детерминированность институциональными, главным образом, экономическими и политическими структурами.

Сторонники новой концептуальной позиции настаивают на том, что изучение форм жизнеобеспечения и социального контроля недостаточны для познания социальных явлений и процессов. Для их объяснения необходимо обратиться к темам коллективных представлений, интерпретации социальных событий, следования сложившимся идеологиям или конструирования новых и т. п. Такие исследователи, как Дж. Александер, П. Бурдье, Э. Гидденс, Р. Уильямс полагают, что социология культуры представляет собой не просто отрасль общественных наук. Речь идет об особом понимании организации совместной жизни людей, отличающемся от ранее утвердившегося в рамках философского и социологического мейнстрима. Их различие характеризуется «не объемом исследуемого явления, а тем, что один и тот же предмет рассматривается ими с различных сторон» [28]. Соответственно объяснительные и прогностические возможности этого теоретического направления увеличиваются по сравнению с преимущественно описательной позицией социологии модерна.

\section{Библиография:}

1. Рорти Р. Послесловие: прагматизм, плюрализм и постмодернизм-1998-Электронный pecypc-http//www. politizdat.ru/article/51/

2. Гидденс Э. Девять тезисов о будущем социологии // THESIS. T. 1. Вып. 1. 1993 (Электронный ресурс$\mathrm{http}: / / \mathrm{www}$. socioline.ru/new)

3. Качанов Ю.Л. Пространство-время социального мира в постструктуралистской перспективе// Неприкосновенный запас. 2010. № 2(70). C. 11. http://magazines.russ./ru/nz/2/lel.html)

4. Кравченко С.А. Социологическое теоретизирование, мышление и воображение в условиях постмодернаЭлектронный ресурc-http://www.isprras.ru/pics/File/postmodern/Kravchenko.pdf

5. Berger P., Luckman T. The Social Construction of Reality-New York: Doubleday, 1966. Р. 12; Бергер П., Лукман Т. Социальное конструирование реальности. Трактат по социологии знания. М.: Медиум, 1995. С. 32.

6. Smith D. Sociological theory: methods of writing patriarchy / Ed. by R.A. Wallace //Feminism and Sociological Theory-Newbury Park, CA: Sage, 1989. P. 34.

7. Frank M. Was ist Neostructuralismus-Frankfurt am. M., 1984. P. 11.

8. Райхман Дж. Постмодернизм в номиналистской системе координат // Флэ-шарт. 1989. № 1. С. 50.

9. Welsch W. Postmoderne - Pluralitat als ethischer und politischer Welt. Köln, 1988. S. 23.

10. Crane D. The Sociology of Culture-Blackwell. Oxford UK and Cambridge USA, 1994. P. 1; Weber M. Wirtschaft und Gesellschaft-Tubingen: Mohr. 1922. S. 13.

11. Mead G.H. Mind, Self and Society-Chicago. University of Chicago Press, 1936. P. 90.

12. Ионин Л.Г. Социология культуры. М.: Логос, 1998. С. 67; Alexander J. The Meanings of Social Life: a Cultural Sociology-N.Y., Oxford University Press. 2003. P. 123.

13. Weber M. Wirtschaft und Gesellschaft-Tubingen, Mohr. 1922. S. 13.

14. Mead G.H. Mind, Self and Society-Chicago, University of Chicago Press, 1936. P. 90. 
15. Манхейм К. Избранное: Социология культуры. М. - СПб., Университетская книга, 2000. С. 256.

16. Александер Дж.С. Аналитические дебаты: Понимание относительной автономии культуры // Социологическое обозрение. Т. 6, № 1 2007. С. 28.

\section{References (transliterated):}

1. Rorti R. Posleslovie: pragmatizm, plyuralizm i postmodernizm-1998-Elektronnyi resurs-http//www.politizdat. $\mathrm{ru} / \mathrm{article} / 51 /$

2. Giddens E. Devyat' tezisov o budushchem sotsiologii // THESIS. T. 1. Vyp. 1. 1993 (Elektronnyi resurs-http:// www.socioline.ru/new)

3. Kachanov Yu.L. Prostranstvo-vremya sotsial'nogo mira v poststrukturalistskoi perspektive// Neprikosnovennyi zapas. 2010. № 2(70). S. 11. http://magazines.russ./ru/nz/2/lel.html)

4. Kravchenko S.A. Sotsiologicheskoe teoretizirovanie, myshlenie i voobrazhenie v usloviyakh postmoderna-Elektronnyi resurs-http://www.isprras.ru/pics/File/postmodern/Kravchenko.pdf

5. Berger P., Luckman T. The Social Construction of Reality-New York: Doubleday, 1966. R. 12; Berger P., Lukman T. Sotsial'noe konstruirovanie real'nosti. Traktat po sotsiologii znaniya. M.: Medium, 1995. S. 32.

6. Smith D. Sociological theory: methods of writing patriarchy / Ed. by R.A. Wallace //Feminism and Sociological Theory-Newbury Park, CA: Sage, 1989. P. 34.

7. Frank M. Was ist Neostructuralismus-Frankfurt am. M., 1984. R. 11.

8. Raikhman Dzh. Postmodernizm v nominalistskoi sisteme koordinat // Fle-shart. 1989. № 1. S. 50.

9. Welsch W. Postmoderne - Pluralitat als ethischer und politischer Welt. Köln, 1988. S. 23.

10. Crane D. The Sociology of Culture-Blackwell. Oxford UK and Cambridge USA, 1994. P. 1; Weber M. Wirtschaft und Gesellschaft-Tubingen: Mohr. 1922. S. 13.

11. Mead G.H. Mind, Self and Society-Chicago. University of Chicago Press, 1936. P. 90.

12. Ionin L.G. Sotsiologiya kul'tury. M.: Logos, 1998. S. 67; Alexander J. The Meanings of Social Life: a Cultural Sociology-N.Y., Oxford University Press. 2003. R. 123.

13. Weber M. Wirtschaft und Gesellschaft-Tubingen, Mohr. 1922. S. 13.

14. Mead G.H. Mind, Self and Society-Chicago, University of Chicago Press, 1936. P. 90.

15. Mankheim K. Izbrannoe: Sotsiologiya kul'tury. M. - SPb., Universitetskaya kniga, 2000. S. 256.

16. Aleksander Dzh.S. Analiticheskie debaty: Ponimanie otnositel'noi avtonomii kul'tury // Sotsiologicheskoe obozrenie. T. 6, № 1 2007. S. 28. 